OESOPHAGUS

\title{
Lifestyle related risk factors in the aetiology of gastro- oesophageal reflux
}

\author{
M Nilsson, R Johnsen, W Ye, K Hveem, J Lagergren
}

Gut 2004;53:1730-1735. doi: 10.1136/gut.2004.043265

See end of article for authors' affiliations

.....................

Correspondence to: Dr M Nilsson, Department of Surgery, Karolinska Hospital, SE-171 76 Stockholm, Sweden; magnus.nilsson@ks.se

Accepted for publication 27 April 2004

\begin{abstract}
Background/Aim: The aetiology of gastro-oesophageal reflux is largely unknown. The authors' aim was to examine the relation between lifestyle habits and gastro-oesophageal reflux symptoms.

Subjects: Participants of two consecutive public health surveys in Nord-Trondelag, Norway.

Methods: In a case control study within the two public health surveys, 3153 individuals who in the second survey reported severe heartburn or regurgitation during the last 12 months were defined as cases, while 40210 people without reflux symptoms constituted the control group. The risk of reflux symptoms was estimated and multivariately calculated as odds ratios in relation to exposure to tobacco smoking, alcohol, coffee, tea, table salt, cereal fibres, and physical exercise.

Results: There was a significant dose response association between tobacco smoking and reflux symptoms. Among people who had smoked daily for more than 20 years the odds ratio was 1.7 (95\% confidence interval 1.5 to 1.9) compared with non-smokers. A similar positive association was found for table salt intake. The odds ratio for reflux was $1.7(95 \% \mathrm{Cl} 1.4$ to 2.0 ) among those who always used extra table salt compared with those who never did so. We found moderately strong negative associations between the risk of reflux and exposure to coffee, bread high in dietary fibre content, and frequent physical exercise. Intake of alcohol or tea did not affect the risk of reflux.

Conclusions: Tobacco smoking and table salt intake seem to be risk factors for gastro-oesophageal reflux symptoms. Dietary fibres and physical exercise may protect against reflux. Alcohol, coffee, and tea do not seem to be risk factors for reflux.
\end{abstract}

G astro-oesophageal reflux disease (GORD) is a considerable health problem in Western societies. The prevalence of reflux symptoms is high, ${ }^{1-3}$ and these symptoms strongly decrease the quality of life of those affected. ${ }^{45}$ Treatment of reflux, both pharmacological and surgical, is very costly. ${ }^{6-8}$ Furthermore, symptomatic GORD is the strongest known risk factor for adenocarcinoma of the oesophagus. ${ }^{9}$

True knowledge about the aetiology of GORD is limited because of a scarcity of valid, population based data of sufficient statistical power. The need to cover this gap of knowledge has recently been emphasised..$^{10}$

A population based study comparing reflux symptoms in monozygotic and dizygotic twins showed that genetic factors might contribute by $31 \%$ to the aetiology of symptomatic GORD. ${ }^{10}$ Although genetic factors are involved, reflux is likely to be caused mainly by environmental factors. ${ }^{10}$ Obesity has recently been established as a risk factor of the internal environment, ${ }^{11}{ }^{12}$ particularly among women. ${ }^{12}$ External environmental factors include various exposures related to lifestyle. Tobacco smoking, alcohol drinking, coffee and tea consumption, as well as regular use of aspirin and other nonsteroidal anti-inflammatory drugs, have all been proposed to be risk factors for reflux. Previous population based studies, though limited in sample size, suggest that tobacco smoking $^{211}{ }^{13}$ and alcohol $^{11}$ may be risk factors for reflux disease. The other exposures listed above were not associated with reflux symptoms in the only previous population based epidemiological study in which they were addressed. ${ }^{11}$ The influence of dietary factors other than coffee and tea, as well as physical exercise have, with the exception of studies of subjectively perceived symptom precipitating factors, ${ }^{14}{ }^{15}$ to our knowledge, not previously been studied in a population based setting.

In the present, large scale, population based study we investigated the role of several lifestyle related exposures in the aetiology of symptomatic GORD. Our hypothesis was that tobacco smoking, alcohol, and coffee cause reflux, whereas dietary fibres and physical exercise may be protective. We further examined tea drinking and table salt intake, without having any biologically grounded hypothesis regarding these exposures

\section{METHODS}

\section{The HUNT public health surveys}

In the Norwegian county of Nord-Trondelag, two extensive public health surveys have been conducted during recent decades. The first survey, Helseundersokelse i NordTrondelag 1 (HUNT 1) was performed in 1984-86 and included 74599 individuals (representing $88.1 \%$ of the population) aged 20 years and above. Data for the second survey (HUNT 2) were collected in 1995-97. That survey included 65363 individuals (representing $71.2 \%$ of the population) aged 20 years and above. A total of 47556 individuals-72.8\% of all HUNT 2 participants-participated in both surveys.

\section{Exposures}

At local temporary research centres, all participants completed extensive written questionnaires covering a wide variety of exposures. In the current study, we specifically analysed variables that were related to lifestyle. These variables included tobacco smoking, use of alcohol, dietary habits, as well as physical exercise. Furthermore, all participating subjects underwent a limited physical examination, including assessment of blood pressure, body weight, and height. In addition, age, sex, and body mass index (BMI; body weight in kilograms divided by the square of body

Abbreviations: GORD, gastro-oesophageal reflux disease; HUNT, Helseundersokelsen i Nord-Trondelag; BMI, body mass index; OR, odds ratio 
height in meters) were assessed as potential confounders. For the potential risk factors and confounders assessed, there were data from HUNT 2-that is, cross sectional data or, in the case of smoking, historic data of lifetime exposure. For alcohol use, table salt use, and physical exercise, there were data from both HUNT 1 (prospectively collected data) and HUNT 2 (cross sectional data). For these exposures, HUNT 1 data were used, in order to lessen the risk of bias from reversed causality - that is, that concomitant occurrence of reflux symptoms would influence the level of exposure.

\section{Definition of reflux disease}

The outcome was defined as severe and recurrent heartburn or regurgitation: the cardinal symptoms of reflux. ${ }^{16-19}$ The outcome was assessed in the HUNT 2 survey only. The subjects answered a question concerning whether they had experienced heartburn or acid regurgitation during the past 12 months and, if so, whether the symptoms were minor or severe. Of the 58596 people in the HUNT 2 survey (90\%) that answered this question, $40210(69 \%)$ had had no such symptoms, 15233 (26\%) had had minor symptoms, and 3153 (5\%) had experienced severe symptoms of reflux. The 3153 subjects reporting severe reflux symptoms were selected to represent the case group and the 40210 without reflux symptoms were chosen as control subjects. The 15233 with minor symptoms were excluded as this group was judged to be too heterogeneous, with considerable risk of misclassification of the outcome.

To evaluate the outcome among people reporting reflux symptoms, we conducted a validation study where the response to the outcome question as posed in the questionnaire was compared with responses to a more extensive reflux symptom questionnaire covering symptom frequency, duration, nightly symptoms, effect of antireflux medication, and impact of the symptoms on everyday life. Out of 1102 outpatients, included at general practitioners in NordTrondelag, the community hospital of Levanger in NordTrondelag, and at the Karolinska Hospital in Stockholm, 103 $(10 \%)$ reported severe symptoms of heartburn or regurgitation during the past 12 months. In this group with severe symptoms, $72 \%$ reported heartburn or regurgitation occurring at least daily or were on daily antireflux medication, 23\% had heartburn or regurgitation once or several times per week, and 5\% had symptoms less frequently than once weekly. Hence, $95 \%$ of the group corresponding to our case group had experienced reflux symptoms at least once per week during the preceding 12 month period. The specificity for symptoms occurring at least once per week in this "sample of cases" was $99.5 \%$ and the corresponding sensitivity was 58\%. Among the 280 (25\%) subjects who reported minor reflux symptoms in the validation study (corresponding to the group excluded from the study), 15\% had daily symptoms or used antireflux medication on a daily basis, $10 \%$ had symptoms at least once per week, and $75 \%$ had symptoms less frequently than once a week. Hence, the majority of people in this sample of those excluded as cases or controls had reflux symptoms occurring less frequently than once per week.

\section{Statistical analyses}

All variables under study were categorised to facilitate unconditional logistic regression analysis. The categories for the number of years of daily tobacco smoking (cigarette, pipe, or cigar) were $<1$ year (reference), 1-5 years, 6-10 years, 1 $1-20$ years, and $>20$ years. The lifetime total number of cigarettes smoked were grouped into $<100$ cigarettes (reference), 101-25 000, $25001-50000,50001-100000$, $100001-200000$, and finally $>200000$ cigarettes. The frequency of alcohol consumption, defined as the number of occasions on which wine, spirits, or beer had been consumed during the preceding two weeks (HUNT 1, prospectively collected data), were grouped into: none (reference), 1-4 occasions, 5-10 occasions, and >10 occasions. Estimated average daily coffee use (HUNT 2, cross sectional data) was categorised into $<1$ cup (reference), $1-3$ cups, 4-7 cups, and $>7$ cups. Daily average tea use (HUNT 2 , cross sectional data) was categorised into $<1$ cup (reference), 1-3 cups, $>3$ cups. Table salt use (HUNT 1, prospectively collected data) was assessed by two variables. Firstly, the average frequency of meals of salted fish or meat was categorised into never (reference), <3/month, once/week, twice/week, and $>$ twice/week. Secondly, the average use of extra salt on regular meals was grouped into never (reference), sometimes, often, and always. Dietary fibre content (HUNT 2, cross sectional data), expressed as the dry weight percentage of the type of bread predominantly consumed, was categorised into plain white bread, 1-2\% (reference); soft medium fibre bread, 4-7\%; soft high fibre content bread, 6-10\%; and finally hard bread, $14-16 \%$. Regular physical exercise of at least 30 minutes duration (HUNT 1, prospectively collected data) was categorised into never (reference), <1/week, 1-3/week, and >3/week. BMI was categorised into $<25,25-30,30-35$, and $>35 \mathrm{~kg} / \mathrm{m}^{2}$.

Odds ratios (OR) and their $95 \%$ confidence intervals (CI), derived from unconditional logistic regression, were used to assess the association between the potential risk factors under study and the risk of reflux symptoms. ${ }^{20}$ Linear trends of the associations were tested by treating categorical variables as continuous in the multivariate model. Potential confounding effects of age, sex, BMI, asthma medication, as well as all the exposure variables under study, were tested by introducing them one by one into the model.

Informed consent was obtained from all participants of the study. The study was approved by the Regional Committee for Medical Research Ethics, Region IV, Norway.

\section{RESULTS}

\section{Age and sex distribution}

The age and sex distribution among the study subjects is presented in table 1. Mean ages were 52 years (case subjects) and 48 years (control subjects). There were no pronounced age differences between sexes.

\section{Tobacco smoking and alcohol consumption}

There was a moderately strong and dose dependent association between increasing duration of daily tobacco smoking of cigarettes, pipes, or cigars and risk of reflux symptoms ( $\mathrm{p}$ value for linear trend $<0.0001$ ) (table 2 ). The multivariate analysis revealed that among individuals who had smoked daily for more than 20 years, the risk of reflux was significantly increased by $70 \%$, compared with those who had smoked daily for less than a year (OR 1.7; 95\% CI 1.5 to

Table 1 Age and sex distribution among cases with reflux symptoms and control subjects without reflux symptoms

\begin{tabular}{llll}
\hline & Men (\%) & Women (\%) & Total (\%) \\
\hline Number of subjects & $1555(7.6)$ & $1598(6.9)$ & $3153(7.3)$ \\
$\quad$ Cases & $18814(92.4)$ & $21396(93.1)$ & $40210(9.7)$ \\
$\quad$ Controls & 50 & 53 & 52 \\
Mean age (years) & 48 & 47 & 48 \\
$\quad \begin{array}{l}\text { Cases } \\
\quad \text { Controls }\end{array}$ & & $20-92$ & $19-101$ \\
Age range (years) & $19-101$ & $19-95$ & $19-99$ \\
$\quad$ Cases & $19-99$ & & \\
$\quad$ Controls & & & \\
\hline
\end{tabular}


1.9). Likewise, there was a dose dependent association between the lifetime total number of cigarettes smoked and reflux symptoms ( $p$ value for linear trend $<0.0001$ ) (table 2 ). Individuals who had smoked more than 50000 cigarettes had a significant $60 \%$ increased risk of reflux symptoms compared with those who had smoked fewer than 100 cigarettes in the multivariate analysis (OR 1.6; 95\% CI 1.4 to 1.8). Alcohol consumption, assessed in HUNT 1, and thus prospectively collected, was not associated with any change in the risk of reflux-independent of the level of consumption (table 2). For both tobacco smoking and alcohol consumption, the multivariately adjusted odds ratios were not markedly different from the unadjusted estimates, indicating lack of strong confounding effects by the variables included in the model (listed in the methods section).

\section{Dietary factors}

Data on the use of coffee and tea were collected from the HUNT 2 survey only, and are therefore of cross sectional nature. In the multivariate analysis there was a negative association between coffee intake and reflux symptoms with an approximate $40 \%$ decrease in risk among people who drank more than seven cups of coffee per day, compared with those who drank less than one cup (OR 0.6; 95\% CI 0.4 to $0.7)$. This finding differed markedly from the univariate analysis of coffee exposure, which showed a slight increase in risk of reflux when comparing the same groups as above (OR $1.2 ; 95 \%$ CI 1.1 to 1.4 ). The analyses revealed that the increased risk of reflux identified in the univariate data could be entirely explained by confounding from tobacco smoking. Tea drinking was not associated with any effect on the risk of reflux symptoms, independent of the adjustment for potential confounding variables (table 3 ).

The use of table salt, based on data from HUNT 1, and thus collected prospectively, was estimated from the frequency of meals of salted fish or meat and from how often the person added extra salt to regular meals. A moderate and dose dependent association between increasing frequency of meals of salted fish or meat and reflux symptoms was observed ( $p$ value for linear trend $=0.0007$ ). The risk of reflux among people who ate salted food three times per week or more was significantly increased by $50 \%$ compared with those who never ate salted food (OR 1.5; 95\% CI 1.2 to 1.8 ). Similarly, the increasing use of extra table salt on regular meals was associated with an increased risk of reflux in a dosedependent manner ( $p$ value for linear trend $<0.0001$ ). The risk of reflux was $70 \%$ increased among people who always added extra salt compared with those who never did so (OR: $1.7 ; 95 \%$ CI 1.4 to 2.0 ) (table 3). With increasing dietary fibre content in the predominantly consumed bread type (HUNT 2; cross sectional data), the risk of reflux decreased significantly ( $\mathrm{p}$ value for linear trend $<0.0001$ ) (table 3 ). People who predominantly ate bread with $7 \%$ dry weight of dietary fibres or more, had an approximately halved risk of having reflux symptoms compared with those who predominantly ate white, low fibre content ( $1-2 \%$ ) bread (OR 0.5 ; $95 \%$ CI 0.4 to $0.7)$. No strong confounding effects were identified in the analyses of dietary salt or fibres (table 3 ).

\section{Physical exercise}

Increasing frequency of physical exercise sessions (HUNT 1 data; prospectively collected) lasting at least 30 minutes, exemplified by jogging, cross country skiing, and exercise swimming, correlated with a decrease in risk of reflux symptoms ( $p$ value for linear trend <0.0001). Physical exercise once a week was associated with a significant, 50\% decreased risk of reflux when compared with individuals who never did any organised physical exercise of at least 30 minutes duration (OR 0.5; 95\% CI 0.4 to 0.7 ) (table 4). Univariate data did not markedly differ from the multivariate results, indicating limited influence of confounding factors.

\begin{tabular}{|c|c|c|c|c|c|c|}
\hline & \multicolumn{2}{|c|}{ Number } & \multicolumn{2}{|c|}{ Univariate } & \multicolumn{2}{|c|}{ Multivariate ${ }^{*}$} \\
\hline & Cases & Controls & $\overline{\mathrm{OR}}$ & $95 \% \mathrm{Cl}$ & OR & $95 \% \mathrm{Cl}$ \\
\hline \multicolumn{7}{|l|}{$\begin{array}{l}\text { Tobacco smoking } \dagger \\
\text { Daily smoking (years) }\end{array}$} \\
\hline$<1$ & 1253 & 20414 & 1.0 & (reference) & 1.0 & (reference) \\
\hline $1-5$ & 133 & 2204 & 1.0 & $(0.8-1.2)$ & 1.2 & $(0.9-1.6)$ \\
\hline $6-10$ & 251 & 3000 & 1.4 & $(1.2-1.6)$ & 1.5 & $(1.2-1.8)$ \\
\hline $10-20$ & 540 & 5583 & 1.6 & $(1.4-1.8)$ & 1.7 & $(1.4-1.9)$ \\
\hline$>20$ & 976 & 9009 & 1.8 & $(1.6-1.9)$ & 1.7 & $(1.5-1.9)$ \\
\hline $\begin{array}{l}\text { p Value for linear trend } \\
\text { Lifetime number of cigarettes smoked } \\
\text { (thousands) }\end{array}$ & & & & & $<0.0001$ & \\
\hline$<0.1$ & 1391 & 21681 & 1.0 & (reference) & 1.0 & (reference) \\
\hline $0.1-25$ & 239 & 3744 & 1.0 & $(0.9-1.1)$ & 1.1 & $(0.9-1.4)$ \\
\hline$>25-50$ & 296 & 3345 & 1.4 & $(1.2-1.6)$ & 1.5 & $(1.3-1.8)$ \\
\hline$>50-100$ & 484 & 4968 & 1.5 & $(1.4-1.7)$ & 1.6 & $(1.4-1.8)$ \\
\hline$>100-200$ & 520 & 4816 & 1.7 & $(1.5-1.9)$ & 1.6 & $(1.4-1.9)$ \\
\hline$>200$ & 223 & 1656 & 2.1 & $(1.8-2.4)$ & 1.6 & $(1.3-2.0)$ \\
\hline $\mathrm{p}$ Value for linear trend & & & & & $<0.0001$ & \\
\hline \multicolumn{7}{|l|}{$\begin{array}{l}\text { Alcohol use } \\
\text { Occasions of spirits, wine, or beer } \\
\text { consumption during last two weeks }\end{array}$} \\
\hline None & 1066 & 11960 & 1.0 & (reference) & 1.0 & (reference) \\
\hline $1-4$ & 776 & 10029 & 0.9 & $(0.8-1.0)$ & 0.9 & $(0.8-1.0)$ \\
\hline $5-10$ & 58 & 695 & 0.9 & $(0.7-1.2)$ & 0.9 & $(0.7-1.2)$ \\
\hline$>10$ & 67 & 655 & 1.1 & $(0.9-1.5)$ & 1.0 & $(0.8-1.3)$ \\
\hline$p$ Value for linear trend & & & & & 0.54 & \\
\hline
\end{tabular}

*In the multivariate logistic regression model adjustments were made for age, sex, body mass index, tobacco smoking, alcohol use, coffee use, and asthma medication. Tea drinking, table salt intake, dietary fibre in bread, and physical exercise were tested in the model, but omitted from the final model because they did not contribute significantly to the explained variance.

†Tobacco smoking and alcohol use variables represent exposure previous to reflux outcome assessment.

$\mathrm{OR}$, odds ratio; $\mathrm{Cl}$, confidence interval. 
Table 3 Dietary factors and risk of symptomatic gastro-oesophageal reflux

\begin{tabular}{|c|c|c|c|c|c|c|}
\hline & \multicolumn{2}{|c|}{ Number } & \multicolumn{2}{|c|}{ Univariate } & \multicolumn{2}{|c|}{ Multivariate* } \\
\hline & Cases & Controls & OR & $95 \% \mathrm{Cl}$ & OR & $95 \% \mathrm{Cl}$ \\
\hline \multicolumn{7}{|l|}{ Coffee use $†$} \\
\hline \multicolumn{7}{|l|}{ Cups per day } \\
\hline$<1$ & 299 & 3955 & 1.0 & (reference) & 1.0 & (reference) \\
\hline $1-3$ & 860 & 10729 & 1.1 & $(0.9-1.2)$ & 0.7 & $(0.6-0.9)$ \\
\hline $4-7$ & 1304 & 18106 & 1.0 & $(0.8-1.1)$ & 0.5 & $(0.4-0.6)$ \\
\hline$>7$ & 593 & 6368 & 1.2 & $(1.1-1.4)$ & & $(0.4-0.7)$ \\
\hline $\mathrm{p}$ Value for linear trend & & & & & $<0.0001$ & \\
\hline \multicolumn{7}{|l|}{ Tea use $†$} \\
\hline \multicolumn{7}{|l|}{ Cups per day } \\
\hline$<1$ & 812 & 10527 & 1.0 & (reference) & 1.0 & (reference) \\
\hline $1-3$ & 880 & 11750 & 1.0 & $(0.9-1.1)$ & 1.0 & $(0.8-1.1)$ \\
\hline$>3$ & 139 & 1365 & 1.3 & $(1.1-1.6)$ & 1.1 & $(0.9-1.5)$ \\
\hline $\mathrm{p}$ Value for linear trend & & & & & 0.20 & \\
\hline \multicolumn{7}{|l|}{ Table salt usef } \\
\hline \multicolumn{7}{|l|}{ Meals of salted fish or meat } \\
\hline Never & 308 & 4057 & 1.0 & (reference) & 1.0 & (reference) \\
\hline$<3 /$ month & 593 & 7746 & 1.0 & $(0.9-1.2)$ & 1.0 & $(0.9-1.2)$ \\
\hline Once/week & 574 & 6839 & 1.1 & $(1.0-1.3)$ & 1.1 & $(1.0-1.3)$ \\
\hline Twice/week & 359 & 3480 & 1.4 & $(1.2-1.6)$ & 1.3 & $(1.1-1.5)$ \\
\hline > Twice/week & 168 & 1367 & 1.6 & $(1.3-2.0)$ & & $(1.2-1.8)$ \\
\hline $\mathrm{p}$ Value for linear trend & & & & & 0.0007 & \\
\hline \multicolumn{7}{|l|}{ Extra salt on regular meals } \\
\hline Never & 905 & 11154 & 1.0 & (reference) & 1.0 & (reference) \\
\hline Sometimes & 717 & 8828 & 1.0 & $(0.9-1.1)$ & 1.1 & $(1.0-1.2)$ \\
\hline Offen & 232 & 2339 & 1.2 & $(1.1-1.4)$ & 1.4 & $(1.2-1.6)$ \\
\hline Always & 146 & 1241 & 1.4 & $(1 \cdot 2-1.7)$ & & $(1.4-2.0)$ \\
\hline $\mathrm{p}$ Value for linear trend & & & & & $<0.0001$ & \\
\hline \multicolumn{7}{|c|}{ Dietary fibres in breadt $\dagger$} \\
\hline \multicolumn{7}{|c|}{$\begin{array}{l}\text { Dry weight \% dietary fibres in bread } \\
\text { predominantly consumed }\end{array}$} \\
\hline 1-2 (white, low fibre) & 177 & 1318 & 1.0 & (reference) & 1.0 & (reference) \\
\hline 4-7 (medium fibre) & 1055 & 12059 & 0.7 & $(0.6-0.8)$ & 0.7 & $(0.6-0.9)$ \\
\hline 6-10 (high fibre) & 921 & 13747 & 0.5 & $(0.5-0.7)$ & 0.5 & $(0.4-0.7)$ \\
\hline 14-16 (hard bread) & 520 & 6742 & 0.6 & $(0.4-0.6)$ & 0.5 & $(0.4-0.7)$ \\
\hline$p$ Value for linear trend & & & & & $<0.0001$ & \\
\hline \multicolumn{7}{|c|}{$\begin{array}{l}\text { *In the multivariate logistic regression model adjustments were made for age, sex, body mass index, tobacco } \\
\text { smoking, coffee use, tea use, table salt intake, and dietary fibres in bread. Alcohol use, physical exercise, and } \\
\text { asthma medication were tested in the model, but omitted from the final model since they did not contribute } \\
\text { significantly to the explained variance. } \\
\text { tData on exposure to coffee, tea, and dietary fibre in bread are of cross sectional nature. } \\
\text { fTable salt data were prospectively collected and represent exposure previous to reflux outcome assessment. } \\
\text { OR, odds ratio; Cl, confidence interval. }\end{array}$} \\
\hline
\end{tabular}

\section{DISCUSSION}

The present study indicates an important role for exogenous exposures in the form of lifestyle related factors in the aetiology of GORD. Exposures associated with an increased risk of reflux symptoms were tobacco smoking and the use of table salt. A reduced risk of reflux was found among people who drank large amounts of coffee, who ate bread high in dietary fibre content, and who frequently exercised. The consumption of alcohol or tea did not affect the risk of reflux.

Strengths of our study include the population based design with high participation rates, reducing the risk of selection bias. Furthermore, the large sample size decreased the risk of chance findings and facilitated subgroup analyses. Moreover, the wide range of exposure data collected made it possible to evaluate a wide range of potential confounding factors in the multivariate analyses. The evaluation of the exposure variables that were assessed before the assessment of reflux - that is, tobacco smoking, alcohol use, table salt use, and physical exercise, had methodological advantages compared with the investigation of present, cross sectional exposure - that is, coffee use, tea use, and intake of dietary fibres in bread. Particularly, the risk of bias from reversed causality is lower; reversed causality in this context meaning that the presence of reflux symptoms would affect the level of exposure under study.

A potential weakness of the study is that reflux was assessed by symptoms only, with a higher risk of misclassification of the outcome, compared with more objective methods, such as $\mathrm{pH}$ measurement or endoscopy. This concern, however, is relieved by the fact that the symptoms used for outcome assessment, namely heartburn and acid regurgitation, are well validated as representative of true GORD. ${ }^{16-19}$ Actually, reflux symptoms are likely to be the best available measure of reflux disease in epidemiological studies. Although the specificity of symptom evaluation might be lower, compared with that of the other available methods, previous studies have found that the specificity is still sufficiently high, especially in subjects with frequent symptoms. ${ }^{16-19}$ Notably, the sensitivity of symptom evaluation is considerably higher than that of the alternative methods. Nevertheless, we separately evaluated the question concerning reflux symptoms in the HUNT 2 survey against a more extensive, previously used reflux symptom questionnaire, ${ }^{9}$ in a validation study. This validation confirmed that the question in the HUNT 2 survey identified people who indicated severe heartburn or regurgitation during the past 12 months (corresponding to the case definition in the main study), and who had at least weekly symptoms, with very high specificity $(99.5 \%)$. Another potential source of error in our study is confounding, which was, however, thoroughly evaluated in our multivariate analyses.

Previous epidemiological studies, ${ }^{211}{ }^{13}$ of cross sectional design and considerably smaller than the present study, have proposed a relation between tobacco smoking and reflux 
Table 4 Physical exercise and risk of symptomatic gastro-oesophageal reflux

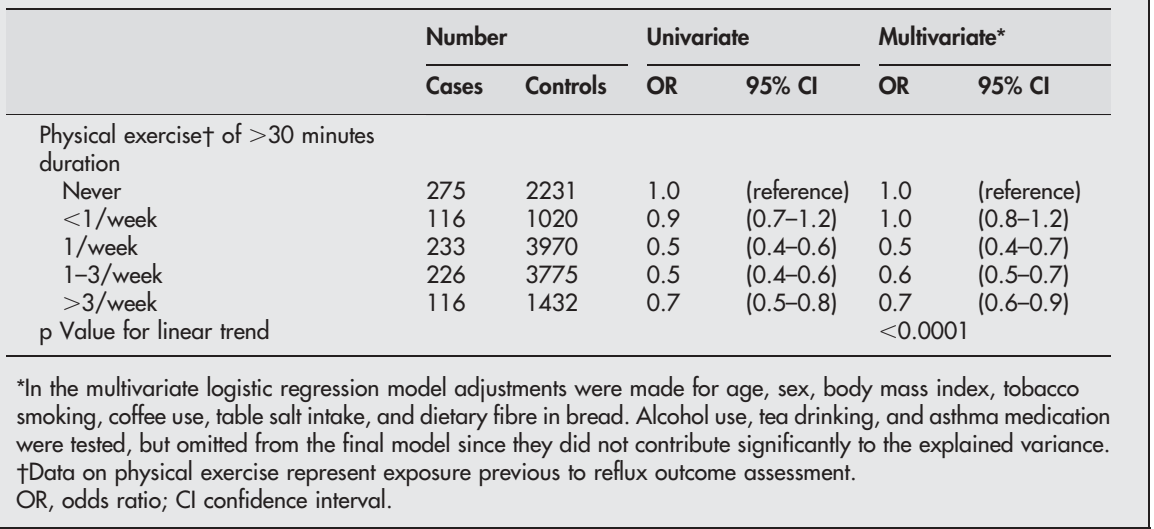

symptoms. Our study strongly suggests that tobacco smoking is a risk factor for reflux symptoms. The tobacco smoking data analysed in this study represent lifetime exposure, and are as such less vulnerable to reversed causality than the corresponding cross sectional exposure data would have been. The consistent dose response relations between both years of daily smoking, and lifetime total number of cigarettes smoked and reflux symptoms, provide convincing evidence that long term tobacco smoking is indeed a risk factor for symptomatic GORD. Experimental studies have shown a reduction of the lower esophageal sphincter pressure and increased frequency of reflux episodes during tobacco smoking, ${ }^{21-24}$ which may be the mechanism behind the association.

Similar to the situation for tobacco smoking, alcohol use has been shown to evoke reflux episodes, ${ }^{25}$ but data concerning long term effects and relation to pathological reflux are limited. The only previous study that, to our knowledge, directly addressed the issue ${ }^{11}$ concluded that alcohol use is a moderate risk factor for reflux symptoms. In the present study, which is larger, and in which alcohol exposure was assessed well ahead of reflux outcome measurement, we found no association between alcohol exposure and the risk of reflux symptoms. The relative risk estimates were generally close to one, independent of the level of alcohol consumption. Hence, our results strongly suggest a lack of association between alcohol and reflux.

Coffee has been reported to precipitate reflux episodes, ${ }^{25} 27$ but previous cross sectional epidemiological studies have not been able to establish that coffee drinking is a risk factor for GORD. ${ }^{11} 28$ In the present study, cross sectional coffee exposure data showed a reduced risk of reflux symptoms among coffee drinkers compared with non-coffee drinkers. Given that it is likely that coffee intake induces symptoms in some susceptible individuals, the risk reduction we observed might be explained by reversed causality: if individuals with reflux symptoms abstain from drinking coffee this would leave a selection of subjects without reflux symptoms among coffee drinkers. The effect of coffee exposure differed markedly when analysed univariately and multivariately, mainly because of positive confounding by smoking. To minimise the influence of reversed causality, and more accurately evaluate the long term effects of coffee drinking on the risk of reflux, an analysis of prospective exposure data would be necessary.

Tea drinking has previously only been studied in a case series of reflux oesophagitis patients and experimentally as a substance that might evoke reflux episodes, ${ }^{28}$ but no significant effect on reflux was seen in either of these studies. In light of these previous negative findings and the data from our present study, tea drinking does not seem to be a risk factor for GORD.

Table salt (sodium chloride) has to our knowledge not previously been evaluated as a risk factor for gastrooesophageal reflux. In the study population from NordTrondelag in Norway, heavily salted fish and meat dishes are an inherent part of the traditional diet, which provided us with an important table salt exposure variable not available in many other populations. The consistent dose response relations, between the frequency of eating salted foods and the risk of reflux symptoms, and between applying extra salt on regular meals and the risk of reflux, indicate that high table salt intake may be a true risk factor for symptomatic GORD. The validity of this association is augmented by the prospective nature of the table salt exposure data, though confounding by other, unknown dietary factors cannot be completely ruled out. As this study is the first to address the relation between salt and reflux, more studies are needed before an association can be established.

Dietary fibres, especially those of cereal origin, have been shown to be associated with a reduced risk of oesophageal and gastric cardia adenocarcinoma, ${ }^{29}$ tumours for which gastro-oesophageal reflux is the main risk factor. ${ }^{9}$ In the present study population, bread is one of the dominating sources of carbohydrates, with most individuals eating two meals per day based on bread. Our cross sectional data on dietary fibre content, of the predominantly consumed bread type, showed a dose-dependent reduction in risk of reflux symptoms with increasing fibre content, suggesting a protective effect against reflux. We can only speculate about the biological mechanism behind this finding. In the acidic environment of the stomach large amounts of nitric oxide are produced non-enzymatically from nitrites in the diet. ${ }^{30}$ Nitric oxide has a potent relaxing effect on the lower oesophageal sphincter, ${ }^{31-33}$ and is as such likely to promote reflux. Dietary fibres are well known to scavenge nitrites in the stomach, ${ }^{29}{ }^{34}$ thereby decreasing the availability of the substrate for nonenzymatic nitric oxide synthesis. This might reduce nitric oxide concentration in the gastro-oesophageal junction, and thus prevent reflux. Given the cross sectional nature of the dietary fibre variable, reversed causality cannot be ruled out, although it seems unlikely as it presupposes that bread with a high fibre content would evoke reflux symptoms, and thus be avoided by reflux prone individuals, a phenomenon which has not been reported.

To our knowledge, the long term effect of physical exercise on the risk of GORD has not been addressed previously. In the present study, prospective data indicate a significant protective effect of regular, at least weekly, physical exercise of 30 minutes duration or more. The mechanism of this 
protective effect could be by strengthening the crural diaphragm, thus possibly improving the function of the part of the antireflux barrier constituted by the striated muscle of the diphragmal crurae. There was no dose response relation, which slightly lessens the credibility of the association. Further studies are needed before the role of physical exercise in reflux aetiology can be established.

In conclusion, our large, population based study provides firm evidence in support of our hypothesis that tobacco smoking causes symptomatic GORD, and some evidence that dietary fibres in bread and physical exercise protect against this disorder. The study further provides sound evidence against our hypothesis that alcohol use causes symptomatic reflux disease, and some evidence against coffee or tea being causally related to reflux. Moreover, our study generates a new hypothesis concerning table salt as a possible long term causal agent behind GORD.

\section{ACKNOWLEDGEMENTS}

We gratefully acknowledge the assistance of the following institutions: The Norwegian Institute of Public Health and the HUNT Research Centre, Verdal, Norway for performing the two HUNT surveys; The HUNT Research Centre, Verdal, Norway and the medical faculty of the Norwegian University of Science and Technology, Trondheim, Norway for allowing access to the database, and AstraZeneca, Sweden and The Swedish Medical Society for financial support.

\section{Authors' affiliations}

M Nilsson, J Lagergren, Department of Surgery, Karolinska Institutet, Karolinska Hospital, Stockholm, Sweden

M Nilsson, W Ye, J Lagergren, Department of Medical Epidemiology and Biostatistics, Karolinska Institutet, Stockholm, Sweden

R Johnsen, K Hveem, Department of Community Medicine and General Practice, Norwegian University of Science and Technology, Trondheim, Norway

K Hveem, HUNT Research Centre, Verdal, Norway

\section{REFERENCES}

1 Ruth M, Mansson I, Sandberg N. The prevalence of symptoms suggestive of esophageal disorders. Scand J Gastroenterol 1991;26:73-81.

2 Isolauri J, Laippala P. Prevalence of symptoms suggestive of gastrooesophageal reflux disease in an adult population. Ann Med 1995;27:67-70.

3 Locke GR 3rd, Talley NJ, Fett SL, et al. revalence and clinical spectrum of gastroesophageal reflux: a population-based study in Olmsted County, Minnesota. Gastroenterology 1997;112:1448-56.

4 Revicki DA, Wood M, Maton PN, et al. The impact of gastroesophageal reflux disease on health-related quality of life. Am J Med 1998;104:252-8

5 Eloubeidi MA, Provenzale D. Health-related quality of life and severity of symptoms in patients with Barrett's esophagus and gastroesophageal reflux disease patients without Barrett's esophagus. Am J Gastroenterol 2000;95: 1881-7.

6 Heikkinen TJ, Haukipuro K, Koivukangas P, et al. Comparison of costs between laparoscopic and open Nissen fundoplication: a prospective randomized study with a 3-month follow up. J Am Coll Surg 1999; 188:368-76.

7 Myrvold HE, Lundell L, Miettinen P, et al. The cost of long term therapy for gastro-oesophageal reflux disease: a randomised trial comparing omeprazole and open antireflux surgery. Gut 2001;49:488-94.
8 Lundell L, Miettinen P, Myrvold HE, et al. Continued (5-year) follow up of a randomized clinical study comparing antireflux surgery and omeprazole in gastroesophageal reflux disease. J Am Coll Surg 2001;192:172-9, discussion 179-81.

9 Lagergren J, Bergstrom R, Lindgren A, et al. Symptomatic gastroesophageal reflux as a risk factor for esophageal adenocarcinoma. N Engl J Med 1999;340:825-31.

10 Cameron AJ, Lagergren J, Henriksson C, et al. Gastroesophageal reflux disease in monozygotic and dizygotic twins. Gastroenterology 2002; 122:55-9.

11 Locke GR 3rd, Talley NJ, Fett SL, et al. Risk factors associated with symptoms of gastroesophageal reflux. Am J Med 1999;106:642-9.

12 Nilsson M, Lundegardh G, Carling L, et al. Body mass and reflux oesophagitis: an oestrogen-dependent association? Scand J Gastroenterol 2002;37:626-30.

13 Haque $\mathrm{M}$, Wyeth JW, Stace $\mathrm{NH}$, et al. Prevalence, severity and associated features of gastro-oesophageal reflux and dyspepsia: a population-based study. N Z Med J 2000;113:178-81.

14 Bolin TD, Korman MG, Hansky J, et al. Heartburn: community perceptions. J Gastroenterol Hepatol 2000; 15:35-9.

15 Oliveria SA, Christos PJ, Talley NJ, et al. Heartburn risk factors, knowledge, and prevention strategies: a population-based survey of individuals with heartburn. Arch Intern Med 1999;159:1592-8.

16 Klauser AG, Schindlbeck NE, Muller-Lissner SA. Symptoms in gastrooesophageal reflux disease. Lancet 1990;335:205-8.

17 Locke GR, Talley NJ, Weaver AL, et al. A new questionnaire for gastroesophageal reflux disease. Mayo Clin Proc 1994;69:539-47.

18 Ter RB, Castell DO. Gastroesophageal reflux disease in patients with columnar-lined esophagus. Gastroenterol Clin North Am 1997;26:549-63.

19 Revicki DA, Wood M, Wiklund I, et al. Reliability and validity of the Gastrointestinal Symptom Rating Scale in patients with gastroesophageal reflux disease. Qual Life Res 1998;7:75-83.

20 Breslow N, Day N. Statistical methods in cancer research. Volume 1. The analysis of case-control studies. IARC Sci Publ, 1980.

21 Waring JP, Eastwood TF, Austin JM, et al. The immediate effects of cessation of cigarette smoking on gastroesophageal reflux. Am J Gastroenterol 1989;84:1076-8.

22 Kahrilas PJ, Gupta RR. Mechanisms of acid reflux associated with cigarette smoking. Gut 1990;31:4-10

23 Sontag SJ, Schnell TG, Miller TQ, et al. The importance of hiatal hernia in reflux esophagitis compared with lower esophageal sphincter pressure or smoking. J Clin Gastroenterol 1991;13:628-43.

24 Kadakia SC, Kikendall JW, Maydonovitch C, et al. Effect of cigarette smoking on gastroesophageal reflux measured by 24 -h ambulatory esophageal $\mathrm{pH}$ monitoring. Am J Gastroenterol 1995;90:1785-90.

25 Nebel OT, Fornes MF, Castell DO. Symptomatic gastroesophageal reflux: incidence and precipitating factors. Am J Dig Dis 1976;21:953-6.

26 Kaufman SE, Kaye MD. Induction of gastro-oesophageal reflux by alcohol. Gut 1978;19:336-8.

27 Brazer SR, Onken JE, Dalton CB, et al. Effect of different coffees on esophageal acid contact time and symptoms in coffee-sensitive subjects. Physiol Behav 1995;57:563-7.

28 Chang CS, Poon SK, Lien HC, et al. The incidence of reflux esophagitis among the Chinese. Am J Gastroenterol 1997;92:668-71.

29 Terry $\mathbf{P}$, Lagergren J, Ye W, et al. Inverse association between intake of cereal fiber and risk of gastric cardia cancer. Gastroenterology $2001 ; 120: 387-91$.

30 Lundberg JO, Weitzberg E, Lundberg JM, et al. Intragastric nitric oxide production in humans: measurements in expelled air. Gut 1994;35:1543-6.

31 Xue S, Valdez D, Collman PI, et al. Effects of nitric oxide synthase blockade on esophageal peristalsis and the lower esophageal sphincter in the cat. Can J Physiol Pharmacol 1996;74:1249-57.

32 Konturek JW, Thor P, Lukaszyk A, et al. Endogenous nitric oxide in the control of esophageal motility in humans. J Physiol Pharmacol 1997;48:201-9.

33 Hirsch DP, Holloway RH, Tytgat GN, et al. Involvement of nitric oxide in human transient lower esophageal sphincter relaxations and esophageal primary peristalsis. Gastroenterology 1998;115:1374-80.

34 Moller ME, Dahl R, Bockman OC. A possible role of the dietary fibre product, wheat bran, as a nitrite scavenger. Food Chem Toxicol 1988;26:841-5. 